\title{
Identification of regulatory elements in the Cyp19 proximal promoter in rat luteal cells
}

\author{
Carlos Stocco, Jakub Kwintkiewicz and Zailong Cai \\ Department of Obstetric, Gynecology and Reproductive Sciences, Yale University School of Medicine, 333 Cedar Street, PO Box 208063, New Haven, Connecticut 06520, USA
}

(Correspondence should be addressed to C Stocco; Email: carlos.stocco@yale.edu)

Z Cai is now at Clinical Research Center, Changhai Hospital, Shanghai 200433, China

\begin{abstract}
The cytochrome P450 aromatase (Cyp19) gene encodes an enzyme of crucial importance in the synthesis of estradiol. Estradiol is luteotropic in the rat. In this species, luteal Cyp19 expression increases progressively during pregnancy and falls before parturition. The mechanisms that control these changes are unknown. Using gel shift assays, we sought to identify the promoter regions that control Cyp19 expression in the rat corpus luteum (CL). The Cyp19 promoter contains a cAMP response element-like sequence (CLS), two nuclear receptor elements half sites (NREs), a GATA binding site, a Yin Yang-1 (YY1) response element, and an activation protein 3 (AP3) binding site. Nuclear extracts were obtained from $C L$ of rats on days 4,15 , and 23 of pregnancy and from the ovaries of immature rats treated with vehicle or a hormone that induces Cyp19 expression in the follicles. CLS was active in immature ovaries but inactive in the CL of pregnant rats, whereas binding to NREs and GATA was observed in both tissues. YY1 was inactive in all samples tested. In the CL, AP3 binding was higher on day 15 of pregnancy when compared with day 4 and day 23 but it was absent in ovaries of immature rats, whereas luteinization increased AP3 binding activity. Mutation of the AP3 site blunted the stimulation of Cyp19 promoter activity in granulosa cells. Our results indicate that CLS is active only in follicles; whereas in the CL, binding to the GATA, NRE, and AP3 sites associates with changes in Cyp19 expression, suggesting that they control Cyp19 promoter activity in luteal cells.
\end{abstract}

Journal of Molecular Endocrinology (2007) 39, 211-221

\section{Introduction}

In rats, luteal function is sustained in part by the luteotropic action of locally produced estradiol (Stocco et al. 2007). Estradiol biosynthesis depends on the expression of the aromatase enzyme. This enzyme is encoded by the Cyp 19 gene. During pregnancy, Cyp19 expression is low on day 4, increases progressively to reach maximal expression from days 15 to 19 , and decreases from day 20 to reach undetectable levels on day 23 (Akinola et al. 1997, Hickey et al. 1988, Stocco 2004). The mechanisms that control the expression of this gene, and therefore estradiol production, in the rat corpus luteum $(\mathrm{CL})$ remain to be determined.

The genomic region located immediately upstream of the coding region (also known as the proximal promoter) drives Cyp19 expression in rat luteal and granulosa cells (GC; Fitzpatrick et al. 1997, Stocco 2004). Within the proximal Cyp19 promoter, a cAMP response element-like sequence (CLS; Hickey et al. 1990), two nuclear receptor elements (NREa and NREb; Fitzpatrick \& Richards 1993a,b, Lynch et al. 1993, Carlone \& Richards 1997b, Michael et al. 1997, Hinshelwood et al. 2003), and a GATA binding element (Jin et al. 2000, Stocco 2004, Kwintkiewicz et al. 2007) have been found.
CLS is essential for the expression of Cyp19 in GCs (Fitzpatrick \& Richards 1994). CLS is recognized by the cAMP response element-binding protein (CREB; Fitzpatrick \& Richards 1994), whereas NRE is recognized by steroidogenic factor-1 (Lynch et al. 1993) and liver receptor homolog-1 (LRH1; Falender et al. 2003, Pezzi et al. 2004). The GATA binding site is recognized by GATA4 in luteal and GCs (Stocco 2004, Kwintkiewicz et al. 2007). GATA4 binding to the Cyp19 promoter is stimulated in vitro and in vivo by follicle-stimulating hormone (FSH) and contributes to the stimulation of Cyp19 expression in GCs (Kwintkiewicz et al. 2007). Transcription factors that bind to the CLS, NRE, and probably to GATA interact in an additive manner to increase Cyp19 expression in rat GCs (Carlone \& Richards 1997a,b, Kwintkiewicz et al. 2007).

The aromatase promoter contains, in addition to the CLS, NRE, and GATA, a binding site for the Yin Yang 1 (YY1) transcription factor and an AP3 binding site (Fig. 1). YY1 is known to have a fundamental role in normal biologic processes such as embryogenesis, differentiation, replication, and cellular proliferation (Gordon et al. 2006). However, the transcription factors that recognize the AP3 binding site are unknown. The AP3 binding site was first identified as a part of the viral

DOI: 10.1677/JME-07-0026 Online version via http://www.endocrinology-journals.org 


\section{-184 CAGAACGTTGACTCTCAATTGAGTATGCACGTCACTCTACCCACT -139 CAAGGGCAAGATGATAAGGTTCTATCAGACCAACCGCTGAACAGG NRE B GATA \\ -94 ACCTGAGTCTCCCAAGGTCATCCTTGTTTTGACTTGTAACCACAA NRE A $\quad$ YY1 AP3 \\ -49 ATTTGTCTTGCCTTGTCACTATAAAACATCTGTCCATTCCAGCAC TATA}

Figure 1 Rat Cyp19 proximal promoter. Transcription factor binding sites are underlined. The numbers on the left indicate the location in relation to the transcription initiation site +1 (Fitzpatrick \& Richards 1993a).

SV40 enhancer, which is composed of multiple sequence motifs acting synergistically to stimulate gene expression (Mercurio et al. 1992). AP3 is essential for maximal SV40 enhancer activity and viral replication (Weiher et al. 1983). Moreover, the AP3 binding site which acts as a tumor-promoter response element (Chiu et al. 1987), is implicated in the up-regulation of $I L-2$ and $I L-2 R$ genes (Emmel et al. 1989, Granelli-Piperno \& Nolan 1991), and activates mRNA transcription during hematopoietic differentiation induced by phorbol esters (Adler \& Kraft 1995). Despite the proven capacity of the AP3 binding site to stimulate transcription, efforts to clone the factors that recognize AP3 have not been successful. Summarizing, in contrast to the established role of the CLS, NRE, and GATA in Cyp19 expression in the ovary, it is not known whether the YY1 and AP3 binding sites are important for Cyp19 expression.

The aim of this investigation was to evaluate the participation of the following binding sites: CLS, GATA, NRE, MY1, and AP3 in the expression of Cyp19 in the rat CL. The capacity of luteal proteins obtained at different stages of pregnancy to bind these sites was evaluated using gel shift analyses. The results indicate that CLS and YY1 are inactive in luteal cells, whereas the GATA, NRE, and AP3 binding sites are recognized by luteal nuclear proteins. Changes in binding to GATA, NRE, and AP3 are associated with changes in Cyp19 expression, suggesting that these sites may regulate Cyp19 expression in luteal cells.

\section{Materials and methods}

\section{Animals and cell culture}

The following protocols were approved by the Yale Animal Resources Center. Sprague-Dawley rats of 26 days of age or timed-pregnant rats of the same strain were obtained from Charles River Laboratories Inc., (Wilmington, MA, USA). Ovaries were collected from 26-day-old immature rats (day 26) treated with pregnant mare serum gonadotropin (PMSG, $15 \mathrm{IU} /$ rat) or vehicle for $48 \mathrm{~h}$. Ovaries were also collected from rats sequentially treated with PMSG for $48 \mathrm{~h}$ and with human chorionic gonadotropin (hCG, $15 \mathrm{IU} / \mathrm{rat}$ ) for $24 \mathrm{~h}$. Corpora lutea were dissected from the ovaries of rats on days 4,15 , and 23 of pregnancy (p4, p15 and p23). Samples were stored at $-80{ }^{\circ} \mathrm{C}$ until nuclear extract isolation. Three animals were included in the experimental groups - d26 and p4, whereas four animals were included in the experimental groups PMSG, PMSG/hCG, and p15 and p23.

Undifferentiated GC were obtained from immature rats treated subcutaneously with estradiol $(1.5 \mathrm{mg} /$ day $)$ for 3 days, whereas luteinized GCs were obtained from immature rats treated with PMSG (15 IU) for $48 \mathrm{~h}$ followed by treatment with hCG (15 IU) for $6 \mathrm{~h}$. In both cases, the ovaries were trimmed to remove the bursa, fat, and oviducts, and incubated for $15 \mathrm{~min}$ at $37^{\circ} \mathrm{C}$ in $6 \mathrm{mM}$ EDTA in Dulbecco's modified Eagle media/ Ham's F-12 media (DMEM/F-12). The ovaries were then incubated for $10 \mathrm{~min}$ in $0 \cdot 6 \mathrm{M}$ sucrose in DMEM/ F-12. The GCs were extracted by puncturing and squeezing the follicles with a 30 -gauge needle. The cells were plated on 24-well plates coated with laminin at a density of $9 \times 10^{4}$ cells/well in DMEM/F-12 serum-free medium supplemented with insulin $(10 \mathrm{mg} / \mathrm{l})$, transferrin $(5.5 \mathrm{mg} / \mathrm{l})$, selenium $(5 \mu \mathrm{g} / \mathrm{l})$, BSA $(0.5 \mathrm{mg} / \mathrm{ml})$, penicillin $\mathrm{G}(100$ units $/ \mathrm{ml})$, streptomycin $(100 \mu \mathrm{g} / \mathrm{ml})$, and amphotericin $\mathrm{B}(250 \mathrm{ng} / \mathrm{ml})$.

\section{RNA isolation and quantitative real-time PCR analysis}

Total RNA from ovaries of immature rats treated with PMSG or from corpora lutea was isolated using TRIzol ${ }^{\circledR}$-Reagent (Invitrogen) following the manufacturer's instructions. For mRNA analysis by RT-PCR, $1 \mu \mathrm{g}$ of the total RNA was reverse-transcribed at $42^{\circ} \mathrm{C}$ using Advantage RT-for-PCR kit (Promega) and later diluted to a final volume of $100 \mu \mathrm{l}$.

To generate standard curves for rat Cyp19 or L19, the cDNA of these genes were cloned into pCR 2.1 vector (Invitrogen), sequenced, and excised by restriction enzyme. Purified cDNA was diluted to concentrations ranging from $10^{3}$ to $6 \times 10^{6}$ copies $/ \mu \mathrm{l}$. Standard cDNA 
or sample cDNA of $5 \mu \mathrm{l}$ aliquots were combined with SYBR Green I (Bio-Rad), specific primers for rat Cyp19 or L19, and water to $50 \mu \mathrm{l}$ final volume. The following intron spanning primers were used to amplify Cyp19: ctgctgatcatgggcctcct and ctccacaggctcgggttgtt and L19: ctgaaggtcaaagggaatgtg and ggacagagtcttgatgatctc. Realtime quantification of the PCR product in each cycle was carried out in an iQcycler Real-time PCR machine (Bio-Rad) with the following cycling conditions: preincubation at $95^{\circ} \mathrm{C}$ for $2 \mathrm{~min}$, followed by 40 cycles of denaturation at $95^{\circ} \mathrm{C}$ for $5 \mathrm{~s}$, annealing at $60^{\circ} \mathrm{C}$ for $10 \mathrm{~s}$, and extension at $72{ }^{\circ} \mathrm{C}$ for $20 \mathrm{~s}$. The melting peak of each sample was routinely determined by melting curve analysis in order to ascertain that only the expected products had been generated. The minimal number of cycles sufficient to produce detectable levels of fluorescence $(\mathrm{Ct})$ was calculated using the MyiQ software (Bio-Rad). The number of Cyp19 or L19 mRNA molecules present in each sample was calculated using a standard curve and expressed as copies per nanogram of total RNA. The results are expressed as the ratio between the copies number per nanogram of total RNA of Cyp19 and ribosomal L19 mRNA.

\section{Transient transfection and luciferase assay}

Undifferentiated or luteinized GCs were transfected with reporter constructs containing 600 or $245 \mathrm{bp}$ of the rat Cyp 19 promoter upstream of the firefly luciferase cDNA (600Cyp19-Luc and 245Cyp19Luc; Cai et al. 2007) or the same promoter carrying a mutation on the AP3 binding site using FuGene 6 transfection reagent (Roche). Transfection efficiency was normalized by co-transfection of the $p C M V$-renilla luciferase expression vector (Promega). After $30 \mathrm{~h}$ of transfection, cells were treated with either FSH $(50 \mathrm{ng} / \mathrm{ml})$ or vehicle for $6 \mathrm{~h}$. Cell lysates were prepared using $100 \mu \mathrm{l}$ of passive lysis buffer (Promega). Luciferase activity was determined in $50 \mu \mathrm{l}$ of lysate/ sample using the Dual Luciferase Reporter Assay (Promega) according to the protocol supplied by the manufacturer. Results are expressed as relative luciferase units normalized to renilla activity.

\section{Electrophoresis mobility shift assay (EMSA)}

Nuclear protein extracts from ovaries or corpora lutea were prepared by extracting nuclei with the following buffer: $0.42 \mathrm{M} \mathrm{NaCl}, 1.5 \mathrm{mM} \mathrm{MgCl}_{2}, 0.2 \mathrm{mM}$ EDTA, $1 \mathrm{mM}$ dithiothreitol, $25 \%$ (v/v) glycerol, $0.5 \mathrm{mM}$ phenylmethylsulfonyl fluoride, $2 \mu \mathrm{g} / \mathrm{ml}$ leupeptin, $2 \mu \mathrm{g} / \mathrm{ml}$ pepstatin $\mathrm{A}, 1 \mu \mathrm{g} / \mathrm{ml}$ aprotinin, and $\mathrm{pH} 7 \cdot 9$. Protein concentration was determined using the BCA assay (Pierce). Complementary oligonucleotides spanning the regions -164 to -143 (CLS), -145 to -125 (NREb), -134 to -116 (GATA), -84 to -71 (NREa),
-76 to -58 (YY1), and AP3 -65 to -47 (Fig. 1) were annealed and labeled with ${ }^{32} \mathrm{P}$ using $\mathrm{T} 4$ kinase. The numbers indicate the location in relation to the transcription initiation site +1 (Fitzpatrick \& Richards $1993 a)$. Nuclear extracts $(5 \mu \mathrm{g})$ were incubated for $20 \mathrm{~min}$ at room temperature in binding buffer $(20 \mathrm{mM}$ HEPES, pH 7.6; $60 \mathrm{mM} \mathrm{KCl,} \mathrm{0.01} \mathrm{mM} \mathrm{ZnSO}_{4}, 0 \cdot 1 \mathrm{mM}$ EDTA, $0.035 \mathrm{mM}$ BSA, $1 \mathrm{mM}$ dithiothreitol, and $6 \%$ glycerol $(\mathrm{v} / \mathrm{v}))$ in the presence of $1 \mu \mathrm{g}$ of salmon sperm DNA and 50000 c.p.m. of radiolabeled double-stranded oligonucleotides. Following incubation, protein-DNA complexes were resolved by electrophoresis in $6 \%$ nondenaturing acrylamide gels. Competitor oligonucleotides were added $10 \mathrm{~min}$ prior to the addition of the probe. Antibodies against nuclear factor of activated T-cells, cytoplasmic, calcineurin-dependent 1(NF-ATc1) (sc13033; Santa Cruz Biotechnology, Santa Cruz, CA, USA) or nuclear factor NF-kappa-B p50 subunit (NFкB p50) (Cat\# 1616737; Geneka Biotechnology, Montreal, Canada) were added 10-40 min prior to the addition of the probe. EMSA assays were performed for each individual animal. Films were scanned and the intensity of band shifts was determined with Image (NIH, Bethesda, MA, USA). The results are expressed as fold increase versus PMSG in Fig. 2 or versus day 4 (p4) in Fig. 3. Three to four animals were used for each group. Representative results are shown.

\section{Protein-DNA crosslinking}

Luteal nuclear proteins were incubated in the presence of ${ }^{32}$ P-labeled AP3 probes for $30 \mathrm{~min}$. Reactions containing a 50-fold excess of wild type or mutant D (Fig. 4B) unlabeled oligonucleotides were also performed. The reactions were exposed to ultraviolet light $(300 \mathrm{~nm}, 50 \mathrm{~W})$ for $20 \mathrm{~min}$ at $4^{\circ} \mathrm{C}$. The samples were denatured with Laemmli sample buffer and run, along with prestained protein molecular markers (Bio-Rad), through $12 \%$ SDS-PAGE gels. Dried gels were developed by autoradiography.

\section{Statistical analysis}

Band shift intensities showed a normal Gaussian distribution. Results are expressed as means \pm s.E.M. and significance was determined using ANOVA I followed by Tukey tests for multiple group comparisons. Significant differences were indicated by $P<0 \cdot 05$.

\section{Results}

\section{Binding of luteal nuclear proteins to the Cyp19 promoter during pregnancy}

To evaluate the participation of the CLS, GATA, NRE, YY1, and AP3 sites on the expression of Cyp19 in the rat 


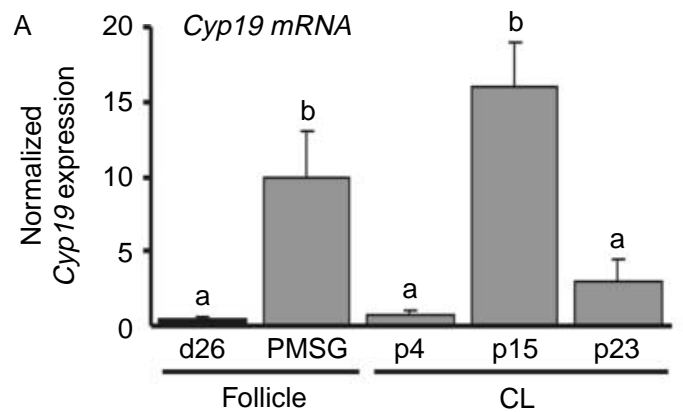

B
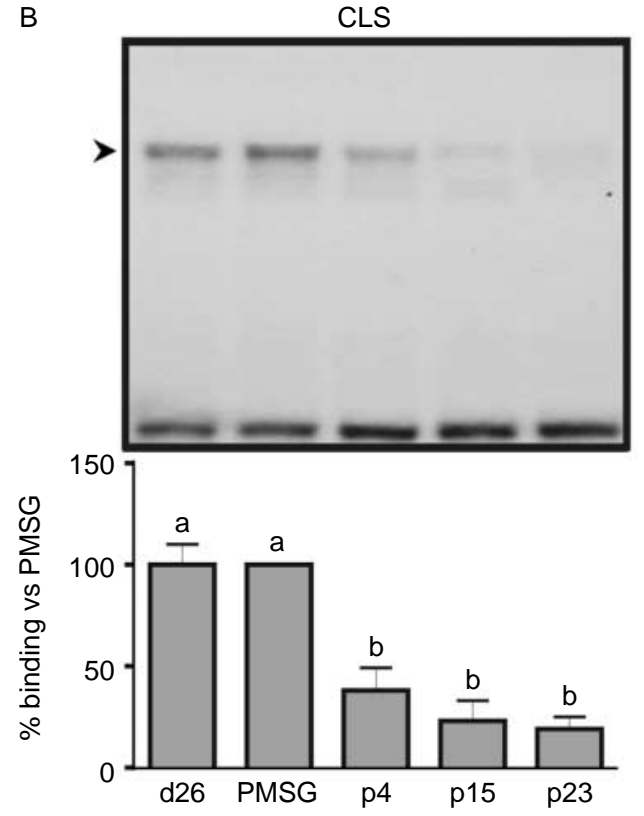

D

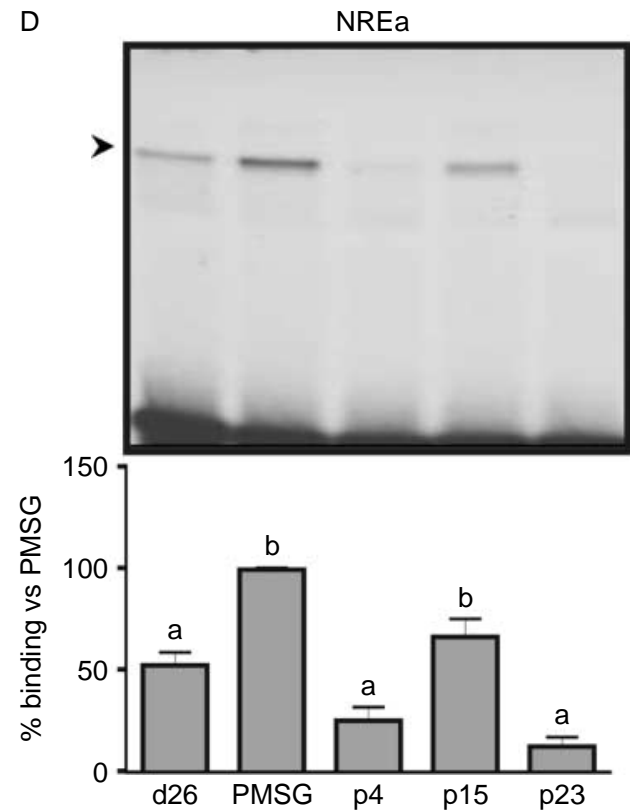

C
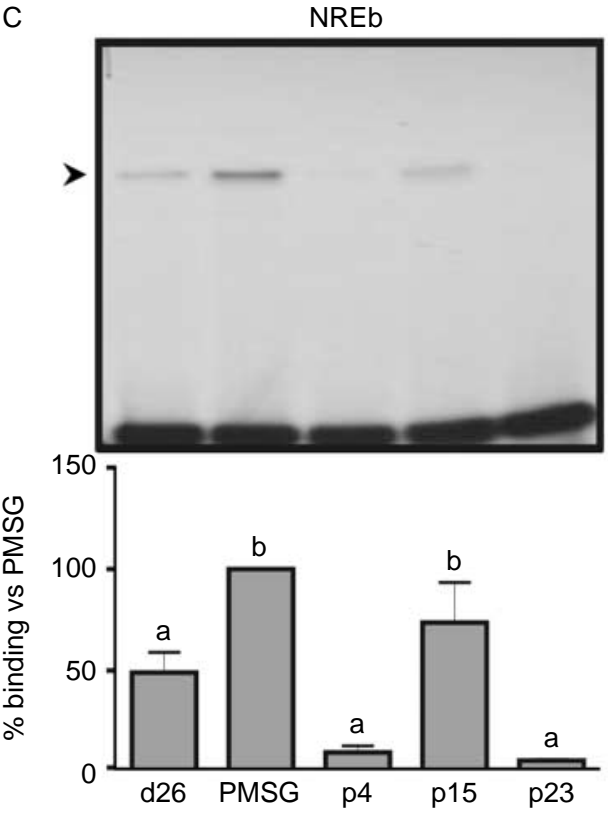

E

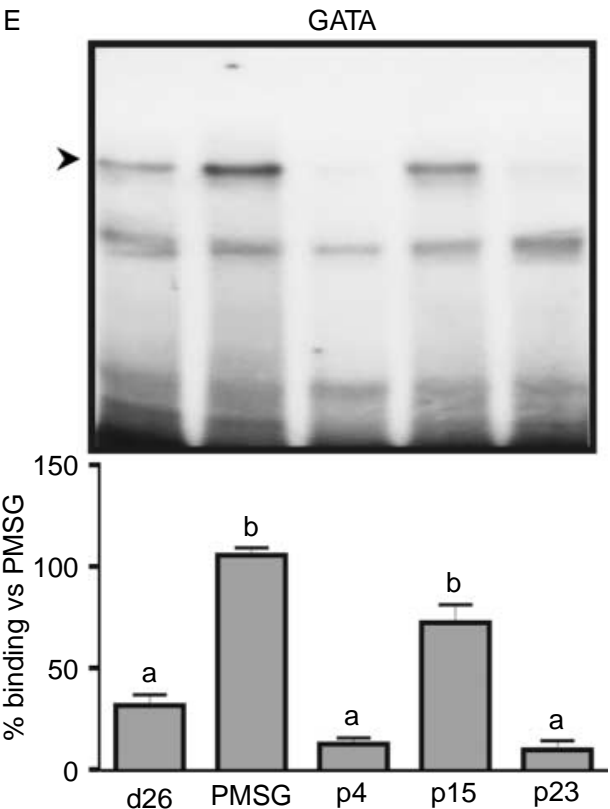


$\mathrm{CL}$, the capacity of luteal nuclear extracts to bind these response elements was investigated. Luteal nuclear extracts were obtained from rats on days 4,15 , and 23 of pregnancy. These days represent maximal (day 15) and minimal (days 4 and 23) levels of Cyp19 expression during pregnancy (Fig. 2A). We also evaluated the binding capacity of nuclear extracts from ovaries of 26-day-old immature rats that do not express Cyp19 and ovaries of immature rats treated with PMSG, a hormone that increases Cyp19 expression in the follicles.

CLS binding activity was high in 26-day-old immature rats and in PMSG-treated rats. However, low CLS binding activity was observed in luteal nuclear extracts from rats on days 4, 15, or 23 of pregnancy (Fig. 2B). Band shift quantification of three independent experiments demonstrated a significant decrease in CLS binding in CL samples when compared with ovarian samples from 26-day-old immature rats or PMSGtreated rats (Fig. 2B).

Binding to the NREa, NREb, and GATA response elements was significantly higher in PMSG-treated rats when compared with 26-day-old rats (Fig. 2C-E). Little or no binding to these elements was detected in luteal nuclear extracts from rats on days 4 and 23 of pregnancy. Binding to NREa, NREb, and GATA was significantly higher in rats on day 15 of pregnancy when compared with days 4 and 23 (Fig. 2C-E).

The addition of a 50-fold excess of unlabeled CLS, NREa, NREb, or GATA oligonucleotides completely prevented the formation of their respective band shifts, whereas a 50-fold excess of mutant oligonucleotides had no effect (data not shown).

No YY1 binding activity was detected in nuclear extracts obtained from ovaries of immature rats or from corpora lutea of pregnant rats (data not shown). On the other hand, nuclear extracts obtained from corpora lutea of pregnant rats showed high AP3 binding activity. As shown in Fig. 3 top panel, low AP3 binding activity was observed in luteal nuclear extracts from rats on day 4 of pregnancy. AP3 binding increased significantly $(P<0 \cdot 01)$ on day 15 of pregnancy and decreased toward the end of pregnancy. No binding to the AP3 binding site was observed before or after PMSG treatment of immature rats. Taken together, these results indicate that the CLS and YY1 binding sites are not active in luteal cells, whereas activation of NRE,
GATA, and AP3 in the CL seems to be developmentally regulated.

\section{AP3 binding increases after the induction of luteinization}

Our results thus far suggest that AP3 binding activity appears only in luteal cells. To examine this hypothesis we examined the effect of the administration of hCG, a hormone that induces ovulation and luteinization, to immature rats pretreated with PMSG for $48 \mathrm{~h}$. As shown in Fig. 4A, ovarian extracts of 26-day-old immature rat or PMSG treated rats did not exhibit AP3 binding activity. In contrast, high AP3 binding activity was observed in ovarian extracts of PMSG/hCG treated animals.

Next, we investigated whether AP3 binding sites are present in the human and mouse proximal promoters. Like rats, humans and mice express Cyp19 in the CL under the control of the proximal promoter (Means et al. 1991, Foyouzi et al. 2005). We also examined the bovine Cyp19 proximal promoter, which is not active in luteal cells (Lenz et al. 2004). AP3 binding sites were found in the human and mouse Cyp19 promoters (Fig. 4B). However, no AP3 sequences were found in the bovine proximal promoter.

\section{Characterization of the luteal AP3 binding protein}

To determine which nucleotides are needed for AP3 binding, two base-pair scanning mutations were introduced into the AP3 oligonucleotide (Fig. 5A). Nuclear extracts from corpora lutea of rats on day 15 of pregnancy were used in these assays. The addition of 50-fold excess of the wild-type oligonucleotide $\mathrm{A}$ or of the mutant oligonucleotides B and G prevented AP3 band shift formation (Fig. 5B, lanes 2, 3, and 8). However, oligonucleotides with mutations in the AP3 site (mutant oligonucleotides $\mathrm{C}, \mathrm{D}, \mathrm{E}$, and $\mathrm{F}$ ) did not affect the formation of the AP3 band shift (Fig. 5B, lanes 4 to 7 ). Next, we performed competitions with increasing concentrations $(5,10,50,100$, and $200 \times)$ of a consensus AP3 oligonucleotide (Mercurio et al. 1992). As shown in Fig. 5C, the AP3 consensus oligonucleotide prevented the formation of the AP3 band shift in a concentrationdependent manner, whereas similar concentrations (50, 100 , and $200 \times$ ) of mutant D did not have an effect.

Figure 2 Binding of luteal nuclear proteins to the CLS, NRE, and GATA response elements. Samples were obtained from ovaries of 26-day-old immature rats (d26), immature rats treated with PMSG, and from corpora lutea of rats on days 4 (p4), 15 (p15), or 23 (p23) of pregnancy. (A) Relative Cyp19 expression levels. Cyp19 and L19 mRNA levels were determined by real-time PCR. Results are expressed as the ratio between the copies number per nanograms of total RNA of Cyp19 and ribosomal L19. (B) Gel shift analyses were performed using oligonucleotides spanning the CLS, (C and D) the nuclear receptor elements a and $b$ (NREa and NREb), or (E) the GATA binding sites found in the proximal Cyp19 promoter (Fig. 1). Three to four animals were included in each group. EMSA assays were performed for each individual animal, representative results are shown. The intensity of each band shift (arrow head) was quantified and expressed as fold increase versus PMSG. Columns with different letters differ significantly $(P<0.05$; ANOVA I-Tukey test). 


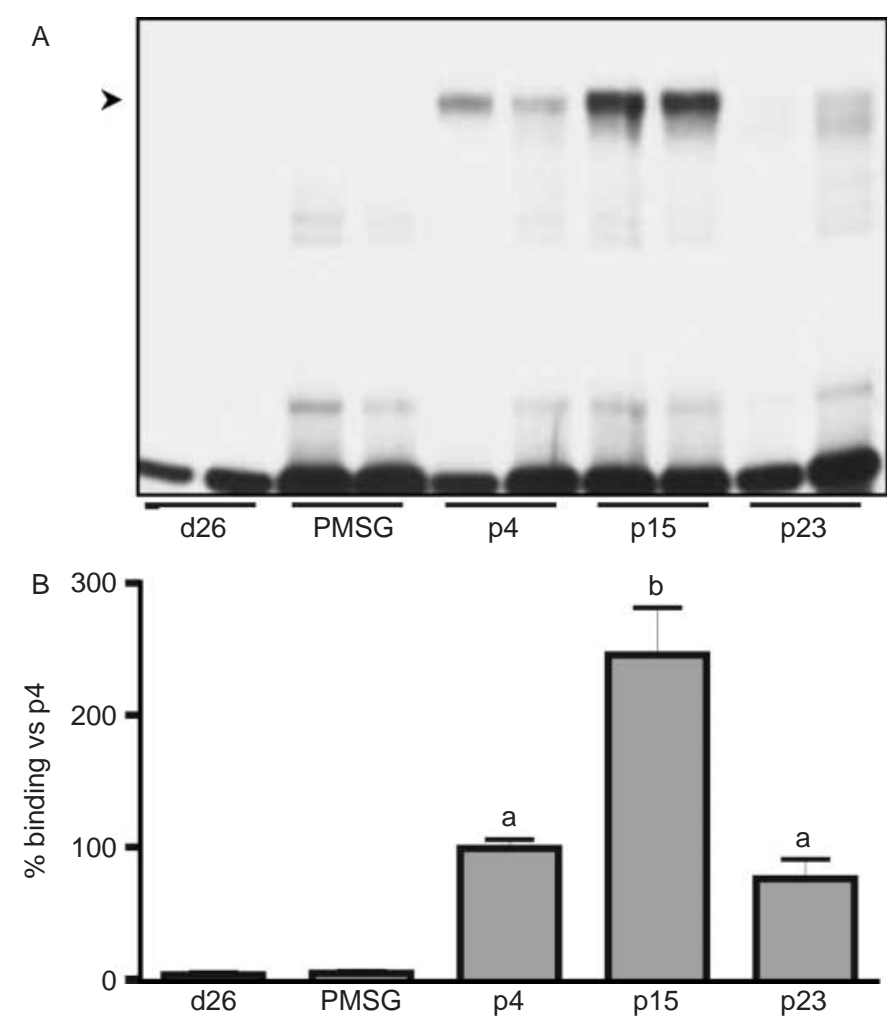

Figure 3 Binding of luteal proteins to the AP3 binding site. (A) Gel shift analysis was performed using oligonucleotides spanning the AP3 region found in the Cyp19 promoter. Three to four animals were used for each experimental group. EMSA assays were performed for each individual animal, representative results are shown. (B) Band shifts (arrow) were quantified and expressed as fold increase versus p4. Columns with different letters differ significantly $(P<0.05$; ANOVA I-Tukey test).

The consensus binding sequence of AP3 is similar to the binding sites of NFKB and NFATc1 (McCaffrey et al. 1992, Lee et al. 2003). Therefore, the possibility arises that the AP3 binding activity found in the rat luteal cells could be due to NFאB or NFATc1. To test this possibility, we added antibodies against these factors to the gel shift reaction. No supershift bands were observed with either an anti-NF $\kappa$ B or an anti-NFATc 1 antibody, suggesting that these transcription factors do not form part of the AP3 complex (Fig. 5D).

The molecular mass of the luteal protein that binds to the AP3 site was determined using DNA/protein crosslink assays followed by denaturing electrophoresis. In good agreement with gel shift assays, a single DNA/protein complex was observed (Fig. 6). The molecular mass of this complex is $\sim 45 \mathrm{kDa}$. The addition to the binding reaction of a 50 -fold excess of a wild-type oligonucleotide prior to the crosslink step decreased the formation of this complex (Fig. 6, lane 2), whereas 50-fold excess of a mutant oligonucleotide (TAACCACA to TAgtCACA) had no effect (Fig. 6, lane 3). This result suggests that a single protein with an apparent molecular mass of $\sim 45 \mathrm{kDa}$ binds to the Cyp19 promoter at the AP3 site.

\section{Mutation of the AP3 binding site decreases Cyp19 promoter activity in GCs}

Next, we examined whether AP3 had any effect on the activity of the Cyp 19 promoter. For this purpose, we used luteinized GCs. We have previously used these cells to study the regulation of Nur77 and 20 $\alpha$-hydroxysteroid dehydrogenase promoters (Stocco et al. 2002). Luteinized GCs were transfected with the 600 Cyp19-Luc or the 245Cyp19-Luc reporter vectors. As a control, cells were transfected with the pCMV-renilla reporter construct. Although the activity of the pCMV-renilla construct was high in all experiments performed, the activity of the 600 Cyp19-Luc or the 245Cyp19-Luc constructs was not detectable in luteinized GCs (data not shown).

In GCs, Cyp19 expression and promoter activity are stimulated by FSH (Kwintkiewicz et al. 2007). Interestingly, we observed that FSH treatment of GCs increases 
A

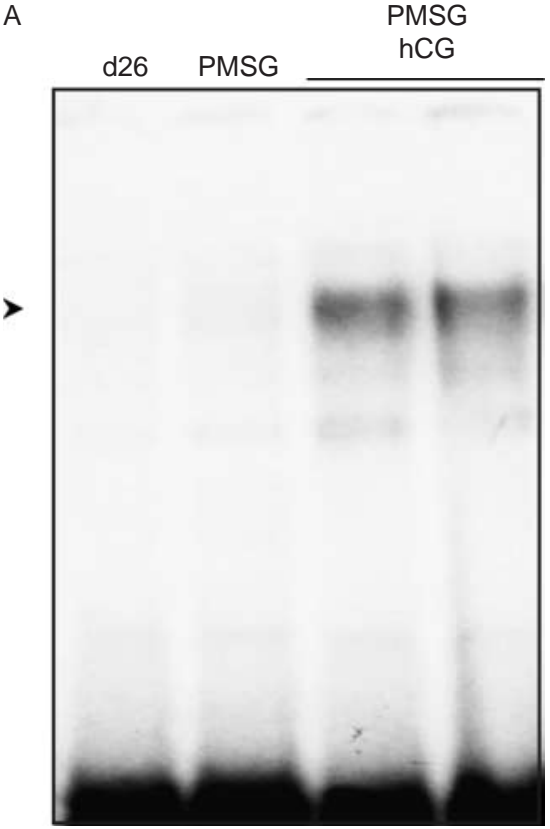

B

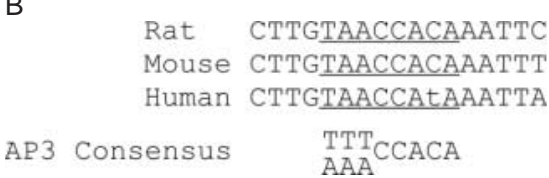

Figure 4 AP3 binding increases after the induction of luteinization. Samples were obtained from ovaries of 26-day-old immature rats (d26), immature rats treated with PMSG for $48 \mathrm{~h}$, or from immature rats sequentially treated with $P M S G$ for $48 \mathrm{~h}$ and with hCG (15 IU/rat) for $24 \mathrm{~h}$. (A) Gel shift analyses were performed using oligonucleotides spanning the AP3 region found in the Cyp 19 promoter. Three animals were used in each group. EMSA assays were performed for each individual animal, representative results are shown. (B) Alignment of the Cyp19 gene regulatory region reveals that the AP3 binding site is conserved in human and rodent species, but is absent from the bovine promoter. The consensus AP3 binding site is noted below the alignment.

binding to the AP3 site. Thus, as shown in Fig. 7A, treatment of GCs with FSH for $48 \mathrm{~h}$ increased AP3 binding. Therefore, we thought to examine whether mutation of the AP3 binding site affects the FSHinduced increase in Cyp19 promoter activity. For this purpose, GCs were transfected with the 245Cyp19-Luc reporter vector or with the mAP3-245Cyp19-Luc construct that contains a mutation in the AP3 site (TAACCACA to TAgtCACA). After transfection, cells were treated with FSH $(50 \mathrm{ng} / \mathrm{ml})$ or vehicle. As expected, FSH treatment of undifferentiated GCs increased Cyp19 promoter activity (Fig. 7B). Mutation of the AP3 binding site significantly decreased the stimulatory effect of FSH, suggesting that AP3 contributes at least in part to the increase in Cyp19 promoter activity induced by this hormone.

\section{Discussion}

In GCs, the CLS is essential for Cyp19 expression (Fitzpatrick \& Richards 1994). However, Cyp19 expression in the rat CL does not correlate with binding to CLS. In luteal cells, Cyp19 expression is affected by cAMP only from days 10 to 12 of gestation (Hickey et al. 1988, 1989). Moreover, in these cells, phospho-CREB resides in the cytoplasmic region, not in the nucleus (Gonzalez-Robayna et al. 1999). This evidence suggests that the cAMP-protein kinase A-CREB pathway is not involved in the regulation of luteal Cyp19expression and further supports our finding showing that the CLS present in the Cyp19promoter is not active in luteal cells.

Our results suggest that luteal Cyp19 expression depends on the activation of GATA, NREs, and AP3 elements. We have previously demonstrated that GATA4 binds to the GATA response element in luteal and GCs (Stocco 2004, Kwintkiewicz et al. 2007). However, the identity of the proteins binding to NRE and AP3 in the CL remains to be determined. NRE is recognized by transcription factors such SF1 (Lynch et al. 1993) and LRH1 (Falender et al. 2003, Pezzi et al. 2004). SF1 is expressed in the CL at levels that are at least one order of magnitude lower than LRH1 (Mendelson et al. 2005). Unfortunately, antibodies against SF1 (Santa Cruz sc-10976) or against LRH1 (Santa Cruz sc-5995 and sc-5997) failed to supershift NRE band shift (data not shown). Whether SF1 or LRH1 is the main factor involved in the regulation of aromatase in the ovary remains to be determined. Both LRH1 and SF1 have been shown to physically interact with GATA4 to synergistically activate the 3ßHSD2 promoter (Martin et al. 2005) and the MIS promoter (Tremblay \& Viger 1999), suggesting that the interaction between GATA4 and LRH1/SF1 may also be important in the regulation of Cyp19 expression in luteal cells.

Binding to NRE and GATA in early pregnancy is significantly lower when compared with preovulatory follicles or CL of rats on day 15 of pregnancy. This finding is supported by previous studies showing that LRH1, SF1, and GATA4 expression decreases during luteinization and increases later in pregnancy (Carlone \& Richards 1997b, Fitzpatrick et al. 1997, Falender et al. 2003, Lavoie et al. 2004, Kwintkiewicz et al. 2007). Administration of prolactin, the main luteotropic hormone in rodents, stimulates the expression of LRH1 in the CL (Falender et al. 2003), suggesting that prolactin may control the expression of LRH1 and Cyp19 in luteal cells. Prolactin regulates Cyp19 expression in the CL of pregnant rats (Hickey et al. 1989, Krasnow et al. 1990). However, prolactin exerts inhibitory or stimulatory effects depending on the stage of pregnancy. For instance, prolactin inhibits Cyp19 expression when administered during the first week of 
A A: CTTGTAACCACAAATT B: CTcgTAACCACAAATT

C: CTTGgCACCACAAATT

: CTTGTAgtCACAAATT

: CTTGTAACtgCAAATT

: CTTGTAACCATCAATT

G: CTTGTAACCACAgcTT

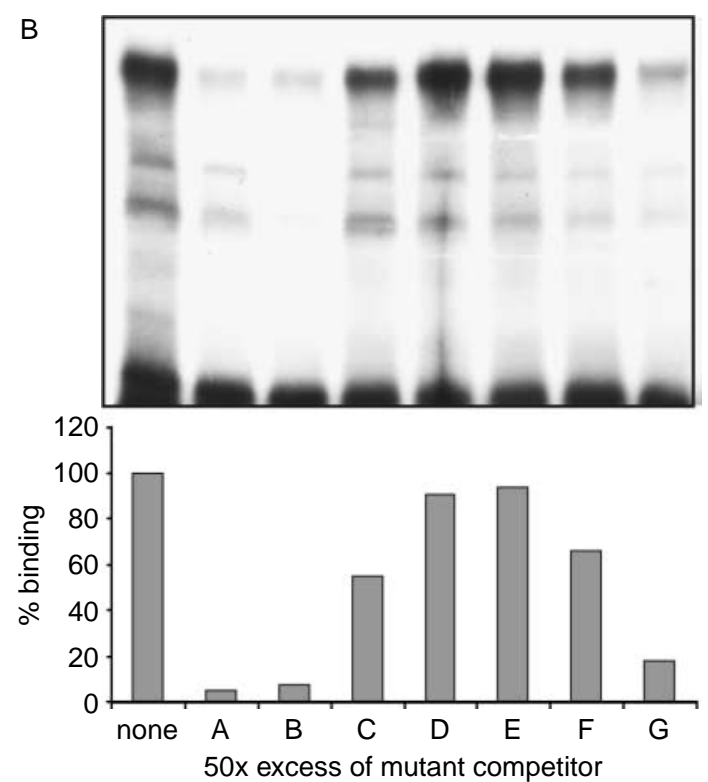

Figure 5 Characterization of luteal AP3 binding protein. (A) Mutant AP3 oligonucleotides used in competition assays. (B) Top panel: Competitions with a 50 -fold excess of unlabeled mutant oligonucleotides of AP3 binding activity observed in rats on day 15 of pregnancy. Bottom panel: Quantification of band shift in upper panel. (C) Competition of AP3 binding with increasing concentrations of unlabeled consensus AP3 oligonucleotides $(5,10,50,100$, and $200 \times)$ or a mutant oligonucleotide (TAACCACA to TAgtCACA; 50, 100, and 200×). (D) Supershift assays: NF-ATc1 and NFKB antibodies were added to nuclear extracts from corpora lutea of rats on day 15 of pregnancy. Samples were also compared with a wild-type unlabeled probe (Cold Ex.).

pregnancy (Krasnow et al. 1990), but increases aromatase expression after day 12 of gestation (Hickey et al. 1989). The molecular basis for this shift is not known. This differential effect of prolactin could be related to its ability to activate or stimulate the expression of transcription factors such as LRH1 and/or GATA4. Further experiments are needed to examine this hypothesis.

We provide evidence indicating that the CL of pregnant rats contains a protein that binds to the AP3 binding site found in the Cyp19 promoter. The AP3 binding site seems to be recognized by a protein with a molecular mass of $48 \mathrm{kDa}$, termed activation protein 3 (Mercurio et al. 1992). Our crosslink experiments revealed that in luteal cells a protein with an apparent molecular mass of $\sim 45 \mathrm{kDa}$ binds to the AP3 binding site. Moreover, gene reporter experiments suggest a role for the AP3 binding site in the activity of the Cyp19 promoter. These results suggest that activation protein 3 is expressed in rat luteal cells and that it may play a role in the regulation of Cyp19 expression.
However, purification and cloning of activation protein 3 are necessary to further examine and confirm its capacity to stimulate Cyp19 expression.

AP3 binding sites are present in the Cyp19 promoter of rats, humans, and mice. These species express high levels of Cyp19 in the CL (Hickey et al. 1988, Foyouzi et al. 2005). Interestingly, AP3 binding sites were not found in the promoter of the bovine Cyp 19 gene. Cyp19 expression in the bovine CL is low when compared with follicles and is controlled by a weak distal promoter (Lenz et al. 2004) instead of a more strong proximal promoter, as in rat, mouse, and human luteal cells (Means et al. 1991, Stocco 2004). AP3 binding site interacts with luteal nuclear extracts from pregnant rats but not with ovarian extracts of immature rats or immature rats treated with PMSG. Moreover, administration of hCG to PMSG-treated rats increases AP3 binding activity suggesting that in vivo this AP3 binding protein is active only in luteal cells. However, we observed that in vitro treatment with FSH increases 


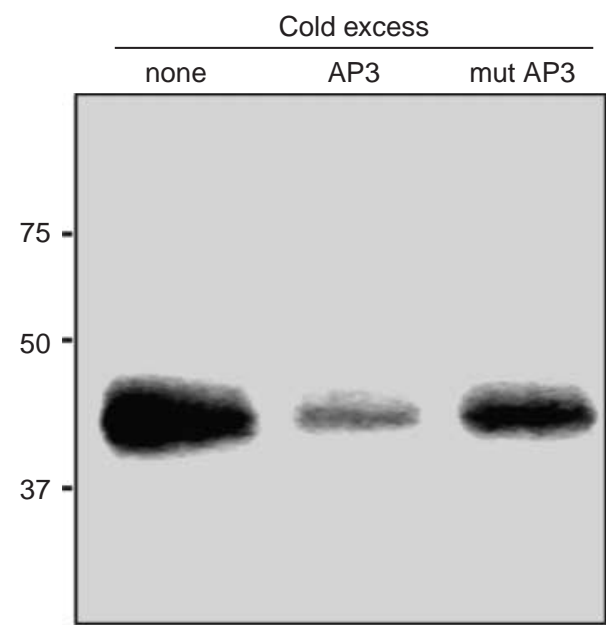

Figure 6 Determination of the molecular mass of the luteal AP3 binding factor. Binding of luteal nuclear extracts from rats on day 15 of pregnancy was carried out as detailed in Material and methods. Binding reactions, including 50 -fold excess of wild type (AP3) or a mutant (mAP3: TAACCACA to TAgtCACA) unlabeled oligonucleotide, were also performed. After exposure to ultraviolet light, the binding reactions were subjected to SDS-PAGE analysis. The gels were then visualized by autoradiography. This experiment was repeated three times with similar results.
AP3 binding activity in GCs. We speculate that this occurs because differentiated GCs luteinize spontaneously in vitro (Luck et al. 1990, Zhao \& Luck 1996, Wehrenberg \& Rune 2000). In PMSG-treated rats, preovulatory GCs are fully differentiated; however, they are prevented from luteinizing prematurely, probably due to inhibitory factors found in the follicular fluid (Ledwitz-Rigby et al. 1977, Channing et al. 1980, Rigby et al. 1980, Bar-Ami \& Channing 1988). In vitro preantral GCs are transformed into preovulatory GCs by the action of FSH (Hunzicker-Dunn \& Maizels 2006). This then allows preovulatory GCs to spontaneously luteinize with the consequent increase in AP3 binding activity.

In conclusion, this is the first report describing the regions in the Cyp19 promoter that could control the expression of this gene in the rat CL. Our results indicate that there are differences between granulosa and luteal cells in the control of the Cyp19 promoter. Thus, whereas CLS is essential for maximal Cyp19 expression in GCs (Fitzpatrick \& Richards 1994), this binding site is not active in luteal cells. On the other hand, transcription factors that bind to NREa, NREb, and GATA seem to participate in the regulation of Cyp19 in both granulosa and luteal cells. We have also
A

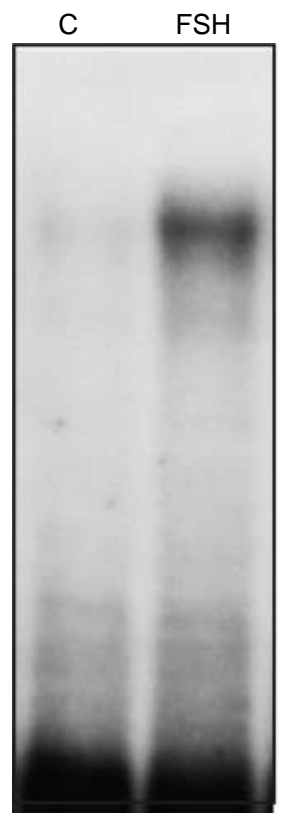

B

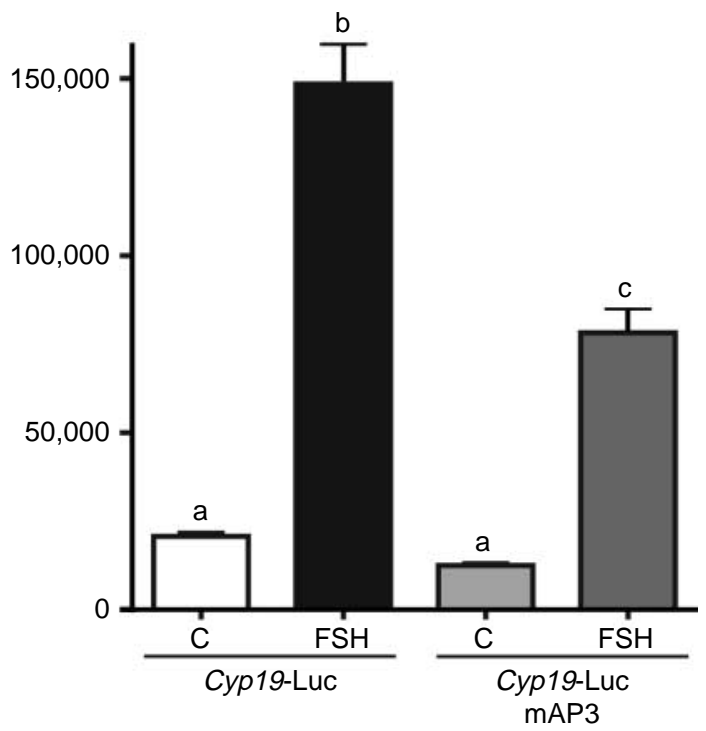

Figure 7 AP3 mutation decreases Cyp19 promoter activity. (A) Gel shift assays were performed with nuclear extracts from undifferentiated granulosa cells treated with FSH $(50 \mathrm{ng} / \mathrm{ml})$ or vehicle $(\mathrm{C})$ for $48 \mathrm{~h}(n=3)$. (B) Undifferentiated granulosa cells were transfected with the 245 bp Cyp19 reporter construct (Cyp19LUC) or the same construct carrying a mutation (TAACCACA to TAgtCACA) in the AP3 binding site (Cyp19Luc mAP3). After transfection, cells were treated with $\mathrm{FSH}(50 \mathrm{ng} / \mathrm{ml})$ or vehicle. Columns with different letters differ significantly ( $P<0 \cdot 01$ : a-b, b-c, and a-c; ANOVA I-Tukey test; $n=4)$. 
demonstrated that luteal cells express a protein that binds to the AP3 binding site found in the proximal Cyp19 promoter.

\section{Acknowledgements}

This investigation was supported by NIH grant HD047427 (CS). The authors declare that there is no conflict of interest that would prejudice the impartiality of this scientific work.

\section{References}

Adler V \& Kraft AS 1995 Regulation of AP-3 enhancer activity during hematopoietic differentiation. Journal of Cell Physiology 164 26-34.

Akinola LA, Poutanen M, Vihko R \& Vihko P 1997 Expression of 17ßhydroxysteroid dehydrogenase type 1 and type 2, P450 aromatase, and $20 \alpha$-hydroxysteroid dehydrogenase enzymes in immature, mature, and pregnant rats. Endocrinology 138 2886-2892.

Bar-Ami S \& Channing CP 1988 Characterization of follicular fluid stimulatory factor upon FSH-induced granulosa cell differentiation. Journal of Endocrinological Investigation 11 777-783.

Cai Z, Kwintkiewicz J, Young ME \& Stocco C 2007 Prostaglandin $\mathrm{E}_{2}$ increases cyp19 expression in rat granulosa cells: implication of GATA-4. Molecular and Cellular Endocrinology 263 181-189.

Carlone DL \& Richards JS $1997 a$ Evidence that functional interactions of CREB and SF-1 mediate hormone regulated expression of the aromatase gene in granulosa cells and constitutive expression in R2C cells. Journal of Steroid Biochemical Molecular Biology 61 223-231.

Carlone DL \& Richards JS $1997 b$ Functional interactions, phosphorylation, and levels of $3^{\prime}, 5^{\prime}$-cyclic adenosine monophosphateregulatory element binding protein and steroidogenic factor-1 mediate hormone-regulated and constitutive expression of aromatase in gonadal cells. Molecular Endocrinology 11 292-304.

Channing CP, Schaerf FW \& Anderson LD 1980 Ovarian follicular and luteal physiology. International Review of Physiology 22 117-201.

Chiu R, Imagawa M, Imbra RJ, Bockoven JR \& Karin M 1987 Multiple cis- and trans-acting elements mediate the transcriptional response to phorbol esters. Nature 329 648-651.

Emmel EA, Verweij CL, Durand DB, Higgins KM, Lacy E \& Crabtree GR 1989 Cyclosporin A specifically inhibits function of nuclear proteins involved in T cell activation. Science 246 1617-1620.

Falender AE, Lanz R, Malenfant D, Belanger L \& Richards JS 2003 Differential expression of steroidogenic factor-1 and FTF/LRH-1 in the rodent ovary. Endocrinology 144 3598-3610.

Fitzpatrick SL, Carlone DL, Robker RL \& Richards JS 1997 Expression of aromatase in the ovary: down-regulation of mRNA by the ovulatory luteinizing hormone surge. Steroids 62 197-206.

Fitzpatrick SL \& Richards JS 1993a Cis-acting elements of the rat aromatase promoter required for cyclic adenosine $3^{\prime}, 5^{\prime}$-monophosphate induction in ovarian granulosa cells and constitutive expression in R2C Leydig cells. Molecular Endocrinology 7 341-354.

Fitzpatrick SL \& Richards JS $1993 b$ Regulation of the rat aromatase gene in ovarian granulosa cells and R2C Leydig cells. Journal of Steroid Biochemical Molecular Biology 44 429-433.

Fitzpatrick SL \& Richards JS 1994 Identification of a cyclic adenosine $3^{\prime}, 5^{\prime}$-monophosphate-response element in the rat aromatase promoter that is required for transcriptional activation in rat granulosa cells and R2C leydig cells. Molecular Endocrinology 8 1309-1319.

Foyouzi N, Cai Z \& Sugimoto Y 2005 Changes in the expression of steroidogenic and antioxidant genes in the mouse corpus luteum during luteolysis. Biology of Reproduction 72 1134-1141.
Gonzalez-Robayna IJ, Alliston TN, Buse P, Firestone GL \& Richards JS 1999 Functional and subcellular changes in the A-kinase-signaling pathway: relation to aromatase and Sgk expression during the transition of granulosa cells to luteal cells. Molecular Endocrinology 13 1318-1337.

Gordon S, Akopyan G, Garban H \& Bonavida B 2006 Transcription factor YY1: structure, function, and therapeutic implications in cancer biology. Oncogene 25 1125-1142.

Granelli-Piperno A \& Nolan P 1991 Nuclear transcription factors that bind to elements of the IL-2 promoter. Induction requirements in primary human T cells. Journal of Immunology 147 2734-2739.

Hickey GJ, Chen SA, Besman MJ, Shively JE, Hall PF, Gaddy-Kurten D \& Richards JS 1988 Hormonal regulation, tissue distribution, and content of aromatase cytochrome $\mathrm{P} 450$ messenger ribonucleic acid and enzyme in rat ovarian follicles and corpora lutea: relationship to estradiol biosynthesis. Endocrinology 122 1426-1436.

Hickey GJ, Krasnow JS, Beattie WG \& Richards JS 1990 Aromatase cytochrome $\mathrm{P} 450$ in rat ovarian granulosa cells before and after luteinization: adenosine $3^{\prime}, 5^{\prime}$-monophosphate-dependent and independent regulation. Cloning and sequencing of rat aromatase cDNA and 5' genomic DNA. Molecular Endocrinology 4 3-12.

Hickey GJ, Oonk RB, Hall PF \& Richards JS 1989 Aromatase cytochrome P450 and cholesterol side-chain cleavage cytochrome $\mathrm{P} 450$ in corpora lutea of pregnant rats: diverse regulation by peptide and steroid hormones. Endocrinology 125 1673-1682.

Hinshelwood MM, Repa JJ, Shelton JM, Richardson JA, Mangelsdorf DJ \& Mendelson CR 2003 Expression of LRH-1 and SF-1 in the mouse ovary: localization in different cell types correlates with differing function. Molecular and Cellular Endocrinology 207 39-45.

Hunzicker-Dunn M \& Maizels ET 2006 FSH signaling pathways in immature granulosa cells that regulate target gene expression: branching out from protein kinase A. Cellular Signalling 18 1351-1359.

Jin T, Zhang X, Li H \& Goss PE 2000 Characterization of a novel silencer element in the human aromatase gene PII promoter. Breast Cancer Research and Treatment 62 151-159.

Krasnow JS, Hickey GJ \& Richards JS 1990 Regulation of aromatase mRNA and estradiol biosynthesis in rat ovarian granulosa and luteal cells by prolactin. Molecular Endocrinology 4 12-13.

Kwintkiewicz J, Cai Z \& Stocco C 2007 Follicle-stimulating hormoneinduced activation of Gata4 contributes in the up-regulation of Cyp19 expression in rat granulosa cells. Molecular Endocrinology 21 933-947.

Lavoie HA, McCoy GL \& Blake CA 2004 Expression of the GATA-4 and GATA- 6 transcription factors in the fetal rat gonad and in the ovary during postnatal development and pregnancy. Molecular and Cellular Endocrinology 227 31-40.

Ledwitz-Rigby F, Rigby BW, Gay VL, Stetson M, Young J \& Channing CP 1977 Inhibitory action of porcine follicular fluid upon granulosa cell luteinization in vitro: assay and influence of follicular maturation. Journal of Endocrinology 74 175-184.

Lee SJ, Lee K, Yang X, Jung C, Gardner T, Kim HS, Jeng MH \& Kao C 2003 NFATc1 with AP-3 site binding specificity mediates gene expression of prostate-specific-membrane-antigen. Journal of Molecular Biology 330 749-760.

Lenz S, Pohland R, Becker F \& Vanselow J 2004 Expression of the bovine aromatase cytochrome $\mathrm{P} 450$ gene $\left(C_{y} p 19\right)$ is primarily regulated by promoter 2 in bovine follicles and by promoter 1.1 in corpora lutea. Molecular Reproduction and Development 67 406-413.

Luck MR, Rodgers RJ \& Findlay JK 1990 Secretion and gene expression of inhibin, oxytocin and steroid hormones during the in vitro differentiation of bovine granulosa cells. Reproduction Fertility and Development 2 11-25.

Lynch JP, Lala DS, Peluso JJ, Luo W, Parker KL \& White BA 1993 Steroidogenic factor 1 , an orphan nuclear receptor, regulates the expression of the rat aromatase gene in gonadal tissues. Molecular Endocrinology 7 776-786.

Martin LJ, Taniguchi H, Robert NM, Simard J, Tremblay JJ \& Viger RS 2005 GATA factors and the nuclear receptors, steroidogenic factor 
$1 /$ liver receptor homolog 1 , are key mutual partners in the regulation of the human $3 \beta$-hydroxysteroid dehydrogenase type 2 promoter. Molecular Endocrinology 19 2358-2370.

McCaffrey PG, Jain J, Jamieson C, Sen R \& Rao A 1992 A T cell nuclear factor resembling NF-AT binds to an NF-kappa B site and to the conserved lymphokine promoter sequence 'cytokine-1'. Journal Biological Chemistry 267 1864-1871.

Means GD, Kilgore MW, Mahendroo MS, Mendelson CR \& Simpson ER 1991 Tissue-specific promoters regulate aromatase cytochrome P450 gene expression in human ovary and fetal tissues. Molecular Endocrinology 5 2005-2013.

Mendelson CR, Jiang B, Shelton JM, Richardson JA \& Hinshelwood MM 2005 Transcriptional regulation of aromatase in placenta and ovary. Journal of Steroid Biochemical Molecular Biology 95 25-33.

Mercurio F, Didonato J, Rosette C \& Karin M 1992 Molecular cloning and characterization of a novel Rel/NF-kappa B family member displaying structural and functional homology to NF-kappa B p50/p105. DNA and Cell Biology 11 523-537.

Michael MD, Michael LF \& Simpson ER 1997 A CRE-like sequence that binds CREB and contributes to cAMP-dependent regulation of the proximal promoter of the human aromatase P450 (CYP19) gene. Molecular and Cellular Endocrinology 134 147-156.

Pezzi V, Sirianni R, Chimento A, Maggiolini M, Bourguiba S, Delalande C, Carreau S, Ando S, Simpson ER \& Clyne CD 2004 Differential expression of Sf-1/Ad4bp and Lrh-1/Ftf in the rat testis: Lrh-1 as a potential regulator of testicular aromatase expression. Endocrinology 145 2186-2196.
Rigby BW, Ledwitz-Rigby F \& Hunzicker-Dunn M 1980 Follicular fluid depression of ovarian granulosa cell adenylyl cyclase activity. Molecular and Cellular Endocrinology 17 17-24.

Stocco C 2004 In vivo and in vitro inhibition of cyp19 gene expression by prostaglandin F2 $\alpha$ in murine luteal cells: implication of GATA-4. Endocrinology 145 4957-4966.

Stocco C, Lau LF \& Gibori G 2002 A calcium/calmodulin-dependent activation of ERK1/2 mediates JunD phosphorylation and induction of nur77 and $20 \alpha$-hsd genes by prostaglandin F2 $\alpha$ in ovarian cells. Journal Biological Chemistry 277 3293-3302.

Stocco C, Telleria C \& Gibori G 2007 The molecular control of corpus luteum formation, function, and regression. Endocrine Reviews $\mathbf{2 8}$ $117-149$.

Tremblay IJ \& Viger RS 1999 Transcription factor GATA-4 enhances Mullerian inhibiting substance gene transcription through a direct interaction with the nuclear receptor SF-1. Molecular Endocrinology 13 1388-1401.

Wehrenberg U \& Rune GM 2000 Spontaneous luteinization of antral marmoset follicles in vitro. Molecular Human Reproduction 6 504-509.

Weiher H, Konig M \& Gruss P 1983 Multiple point mutations affecting the simian virus 40 enhancer. Science 219 626-631.

Zhao Y \& Luck MR 1996 Bovine granulosa cells express extracellular matrix proteins and their regulators during luteinization in culture. Reproduction Fertility and Development 8 259-266.

Received in final form 21 July 2007

Accepted 30 July 2007

Made available online as an Accepted Preprint

30 July 2007 